\title{
Radiation Characteristic Improvement of X-Band Slot Antenna Using New Multiband Frequency-Selective Surface
}

\author{
Elham Moharamzadeh \\ Electrical Engineering Department, Islamic Azad University, South Tehran Branch, Tehran 4435, Iran \\ Correspondence should be addressed to Elham Moharamzadeh; st_e_moharamzade@azad.ac.ir
}

Received 23 December 2013; Revised 7 July 2014; Accepted 6 August 2014; Published 14 October 2014

Academic Editor: Francisco Falcone

Copyright (C) 2014 Elham Moharamzadeh. This is an open access article distributed under the Creative Commons Attribution License, which permits unrestricted use, distribution, and reproduction in any medium, provided the original work is properly cited.

\begin{abstract}
A new configuration of frequency-selective surfaces (FSSs) is designed and presented with multiresonance characteristics which covers all of the frequency domain of X-band from 8 to $12 \mathrm{GHz}$. The proposed FSS comprises three conductor-based split ring resonators, connected together. In this design, two unit cells of the FSS with different lengths are employed side by side to design the FSS. The FSS is used to enhance the gain of the new designed triangle slot antenna at X-band. The proposed FSS is analyzed by using reflected-wave unit-cell box method. The single, double, and array of the FSS cells are studied. Next, the designed FSS along with the antenna is analyzed. The measurement and simulated results of the impedance and radiation characteristics, especially the increment of the gain, are presented.
\end{abstract}

\section{Introduction}

For wireless communications, developments of periodic structures especially frequency-selective surface (FSS) demonstrate their ability in solving some of the key aspects in antenna technology. FSS is first demonstrated by Munk [1]. Most commonly used applications of the FSS are radar and absorbers [2], Radome design [3], and telecommunication [4]. The FSS structure could be also used as a high impedance surface (HIS) to provide maximum angular stability for horizontal and vertical polarizations to the phase of resonant frequency [5]. HIS is mostly used to enhance the antenna bandwidth and gain, because it provides maximum reflection to the fringing waves [6]. In the literature, multilayer FSS was employed to especially enhance the gain of the various antennas, such as semicircular slot [7], WCDMA dipole [8], $60 \mathrm{GHz}$ patch [9], and cavity resonance [10] antennas. To meet the requirements of those application purposes, many aspects should be considered at the design stage of FSSs: selection of the proper FSS geometry, electrical properties of dielectric material, spacing between unit cells, and so on [11]. There have been several techniques to obtain multiple resonance properties, such as a unit cell with geometrically the same shape but different sized elements [11] or with fractal geometry [12]. For this purpose, dual-band FSS in [13] and multiband artificial magnetic conductor (AMC) in [14] have been presented and studied.

In this paper, first, similar to the slot antenna in $[15,16]$, a new modified triangle slot antenna is designed to operate inside the X-band from 8 to $12 \mathrm{GHz}$. In this design, two rectangular slits are added in the edge of the radiating slot as a capacitance to adjust and improve the impedance matching and bandwidth. Afterwards, the gain enhancement of the antenna is studied. For this purpose, three split ring resonators are connected together as a unit cell of FSS. To excite the multiresonance, a combination of two unit cells of the proposed FSS side by side with different parameters (lengths) is designed. The reflected-wave unit-cell box method is used to analyze each of the FSS configurations, the combination of them, and the final FSS. Next, the designed FSS as a perfect reflector along with the slot antenna is considered to study the final return loss and gain of the antenna-FSS prototype. Finally, the best sample of the antenna-FSS was selected and manufactured. All results along with the related discussions are presented in the following. 


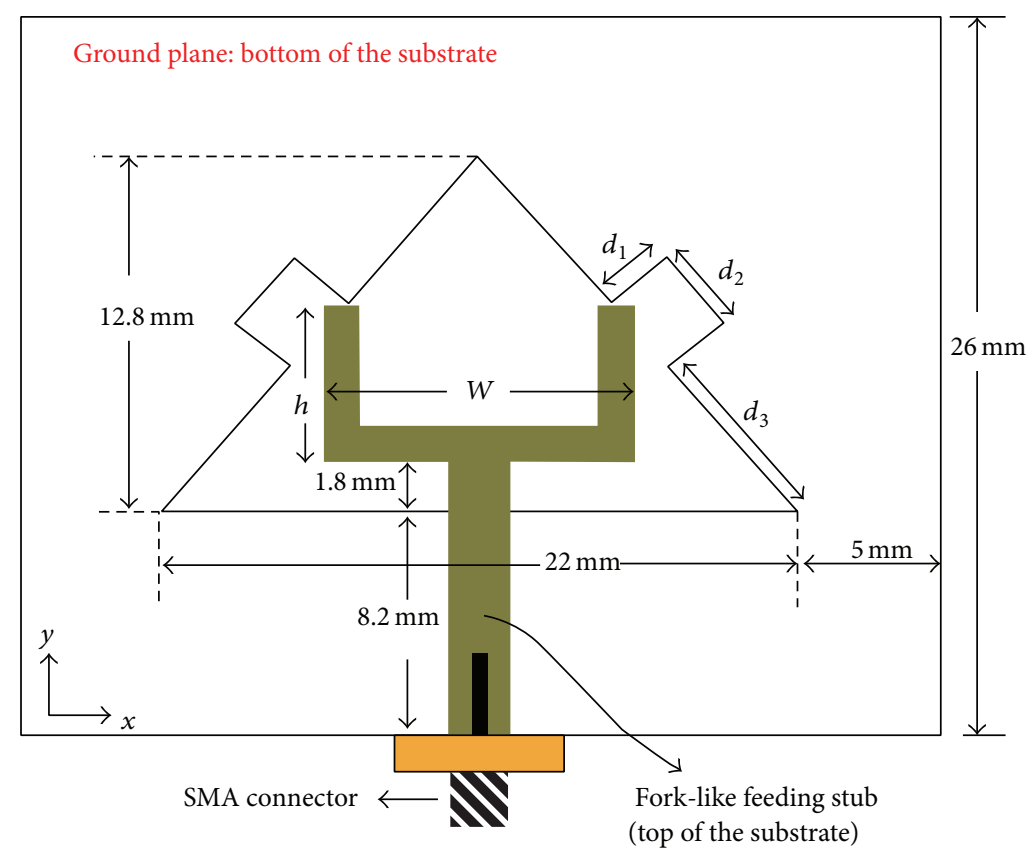

(a)

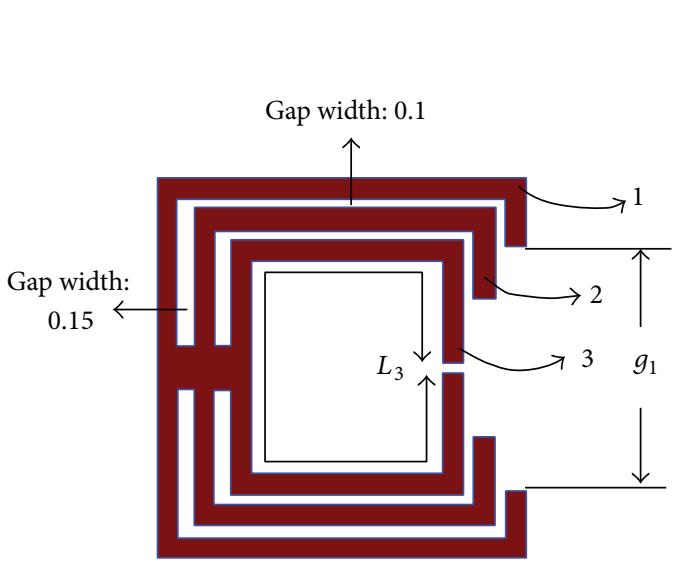

(b)

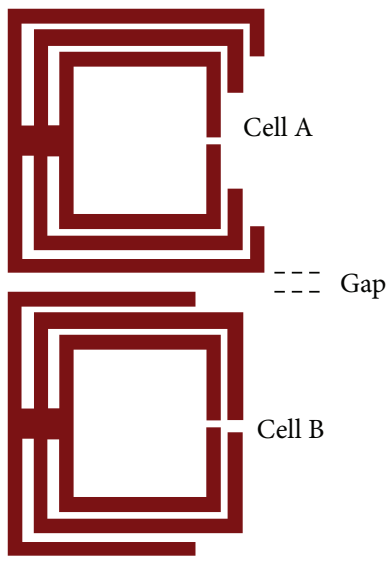

(c)

FIGURE 1: Geometry and design parameters of the proposed: (a) microstrip slot antenna, (b) unit cell of the FSS screen, and (c) combination of two cells.

\section{Geometry and Design of Slot Antenna and FSS}

Figure 1(a) shows that the slot antenna using FR4-based substrate $\left(\varepsilon_{r}=4.4, \tan \delta=0.02\right)$ with dimension of $32 \times 26 \times$ $1.6 \mathrm{~mm}^{3}$ consists of a triangle radiating slot with two slits with parameters of $d_{1}, d_{2}$, and $d_{3}$ and a fork-like feed stub with two arms (width $=1.2 \mathrm{~mm}$ ). Key parameters of the stub, $W$ and $h$, control the coupling into the triangle aperture $[15,16]$. These parameters affect the antenna matching and bandwidth which will be carefully studied and selected. A microstrip line with a width of $2 \mathrm{~mm}$ is connected to the fork-like stub to feed the antenna. Here, to generate symmetric structure and radiation characteristic and more coupling between the slits and feeding stub, both of the added slits are approximately placed in the middle of the diagonal edges of the triangle slot with a length of about $16 \mathrm{~mm}$. Therefore, the value of $d_{3}$ is selected to be about $6.7 \mathrm{~mm}$.

To design a new FSS structure with three resonances within the X-band from 8 to $12 \mathrm{GHz}$, three metallic square ring resonators are connected together with different lengths as a unit cell, established on a $1 \mathrm{~mm}$ FR4-based substrate, as illustrated in Figure 1(b). The width and length values at each ring are $0.2 \mathrm{~mm}$ and $L_{i}$, respectively, where $i$ is the index of the ring $(i=1,2,3)$. The gap between two heads of every ring is $g_{i}(i=1,2,3)$, as can be seen in Figure $1(\mathrm{~b})$. In addition, the width of the gap between every two rings is about 0.15 and $0.1 \mathrm{~mm}$, shown in Figure 1(b). In order to more cover the X-band, we need to excite the other resonances near the previous resonances, excited by the first cell. Therefore, the second cell with different lengths is employed side by side, as shown in Figure 1(c). The proposed configuration as an array 


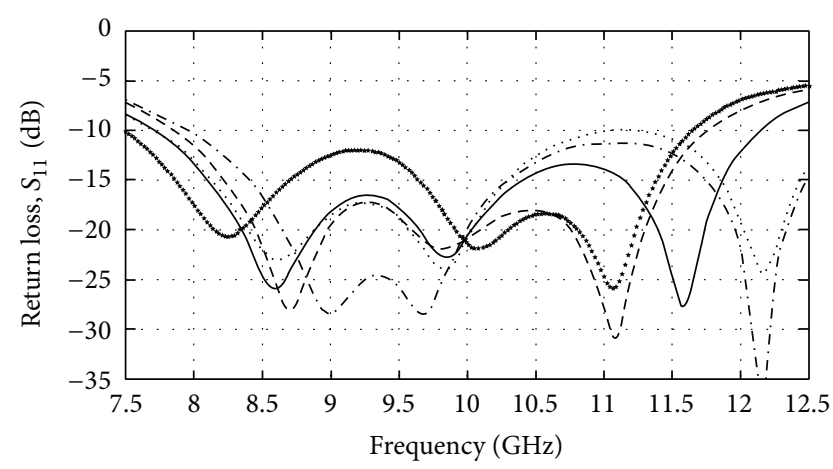

$$
\begin{aligned}
& \cdots W=10 \mathrm{~mm}, h=5.7 \mathrm{~mm} \quad \cdots W W=10.7 \mathrm{~mm}, h=5.2 \mathrm{~mm} \\
& \cdots \cdots * W=11.5 \mathrm{~mm}, h=5.7 \mathrm{~mm} \quad---W=10.7 \mathrm{~mm}, h=6.2 \mathrm{~mm} \\
&-W=10.7 \mathrm{~mm}, h=5.7 \mathrm{~mm}
\end{aligned}
$$

(a)

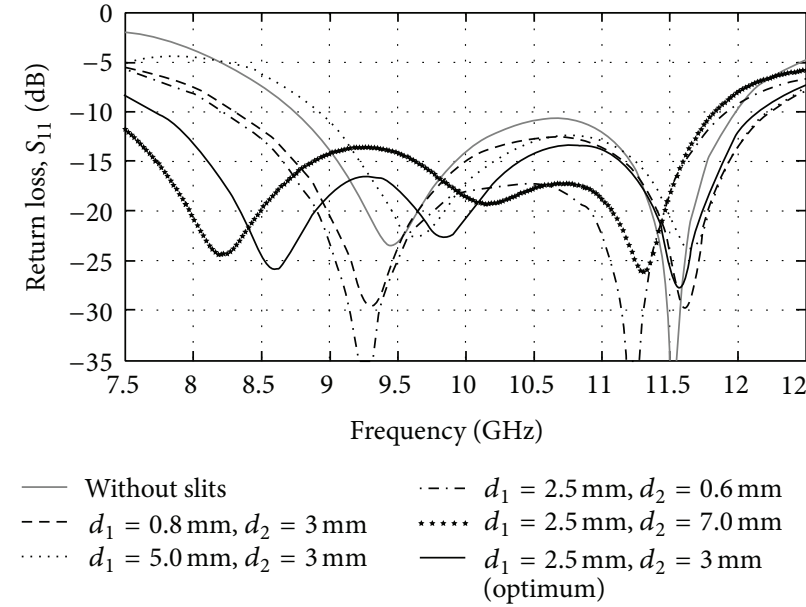

(b)

Figure 2: Simulated return losses of the antenna without FSS (see Figure 1(a)) for different values of (a) $W$ and $h$ in the feeding stub $\left(d_{1}=2.5\right.$ and $\left.d_{2}=3 \mathrm{~mm}\right)$ and (b) $d_{1}$ and $d_{2}$, the parameters of the slits $\left(W=10.7, h=5.7\right.$, and $\left.d_{3}=6.7 \mathrm{~mm}\right)$.

format, called FSS screen, is used in top of the slot antenna surface with a variable height and optimized to obtain the maximum possible value of the gain.

\section{Simulation, Parametric Study, and Discussion}

The parametric analysis of the design is done by using Ansoft HFSS EM simulation tool.

3.1. Triangle Slot Antenna Design. The effect of the variation of the key parameters of the proposed triangle slot antenna, $W, h, d_{1}$, and $d_{2}$ shown in Figure 1(a), on the return loss is presented in Figure 2. First, three values of $W$ and $h$ are selected and studied. Figure 2(a) shows that, by increasing $W$ from 10 to $11.5 \mathrm{~mm}$ and hence the electrical length of the stub when $h$ is constant, the lowest and highest edges of the band (for $\mathrm{S}_{11}=-10 \mathrm{~dB}$ ) are decreased about 0.5 and $1.3 \mathrm{GHz}$, respectively. In addition, by increasing $W$, the matching of the lower frequencies from 8.5 to $10 \mathrm{GHz}$ is degraded. But, the matching between 10 and $11.5 \mathrm{GHz}$ is improved. Therefore, selecting the median value of $W$, about $10.7 \mathrm{~mm}$, is suitable. As can be seen in Figure 2(a), by increasing $h$, only the highest edge of the bandwidth is decreased or the position of the third resonance is changed from 12.2 to $11.1 \mathrm{GHz}$. Hence, to accurately cover the X-band, the value of $h$ is selected to be about $5.7 \mathrm{~mm}$. To analyze the performance of the slits, the return loss of the triangle slot antenna without slits is also presented for comparison. Figure 2(b) clarifies that without slits only two resonances at 9.5 and $11.5 \mathrm{GHz}$ with poor matching and bandwidth can be obtained. By adding the slits, the other resonance is excited in the lower frequencies of the band, so the bandwidth and matching are improved, considerably. It is interesting to note that by selecting $d_{2}=$ $0.6 \mathrm{~mm}$ only two resonances at 9.25 and $11.25 \mathrm{GHz}$ are excited. By increasing $d_{2}$ greater than $1 \mathrm{~mm}$, the third resonance between 8 and $8.7 \mathrm{GHz}$ is excited. This case is again seen when $d_{1}=0.8 \mathrm{~mm}$. This phenomenon occurs because when $d_{1}$ and $d_{2}$ are very small the related capacitors at the edges of the triangle slot and the resonances are not generated. To obtain the better matching and wider bandwidth inside the X-band, Figure 2(b) clarifies that the best values of $d_{1}$ and $d_{2}$ are about 2.5 and $3 \mathrm{~mm}$, respectively.

3.2. Reflected-Wave Unit-Cell Box Analysis of the FSS. First, the proposed FSS unit cell is studied. The setup configuration of the reflected-wave unit-cell box study is illustrated in Figure 3. The thickness of the FR4-based substrate is $1 \mathrm{~mm}$. For this study, a unit cell with proper periodic boundary conditions on its four sides, including the Perfect $\mathrm{E}$ for right and left sides and the Perfect $\mathrm{H}$ for the front and back sides, is excited by two wave ports at the beginning and the end of the box, as can be seen in the figure. Here, to create symmetry in the reflected phase response near the $0^{\circ}$, the distance between the ports and the surface of the unit is selected to be about $\lambda_{0} / 4$ or $7.6 \mathrm{~mm}$ at $10 \mathrm{GHz}$. Figure 3 also shows the results of only the first cell or Cell A, shown in Figure 1(c). The $S_{21}$ resonances, related to the nearly zero reflections of the FSScell surface, are about $8.45,10.1$, and $11.4 \mathrm{GHz}$. In addition, a relatively flat-phase response (between $+50^{\circ}$ and $-50^{\circ}$ ) of the reflection coefficient can be seen over the whole band, from 8 to $12 \mathrm{GHz}$, using the first cell. The smallest ring resonator with parameter of $L_{3}$ excites the third resonance at $f_{3}=11.4 \mathrm{GHz}$ and so on and similar is the case for the other rings. The best values of the parameters are as follows: $L_{1}$ is $11.1 \mathrm{~mm}$ that is about $0.59 \lambda_{g}\left(\lambda_{g}\right.$ : the guided wavelength at $8.45 \mathrm{GHz}$, $\left.\lambda_{g}=18.65 \mathrm{~mm}\right), L_{2}$ is $9.6 \mathrm{~mm}=0.6 \lambda_{g}\left(\lambda_{g}=15.89 \mathrm{~mm}\right.$ at $10.1 \mathrm{GHz})$, and $L_{3}$ is $8.3 \mathrm{~mm}=0.59 \lambda_{g}\left(\lambda_{g}=14.1 \mathrm{~mm}\right.$ at $11.4 \mathrm{GHz})$. Here, $\lambda_{g}=\lambda_{0} / \sqrt{\varepsilon_{\text {reff }}}\left(\varepsilon_{r}=4.4, h=1 \mathrm{~mm}\right.$, and $\left.\varepsilon_{\text {reff }}=3.56\right)$. Also, $g_{1}=2.3, g_{2}=1.3$, and $g_{3}=0.15 \mathrm{~mm}$. By using this technique and the related parameters, the second cell, Cell B, is designed. In this case, the values of $L_{1}, L_{2}$, and $L_{3}$, determined for Cell $\mathrm{B}$, are $8.6,10.8$, and $8.3 \mathrm{~mm}$, 

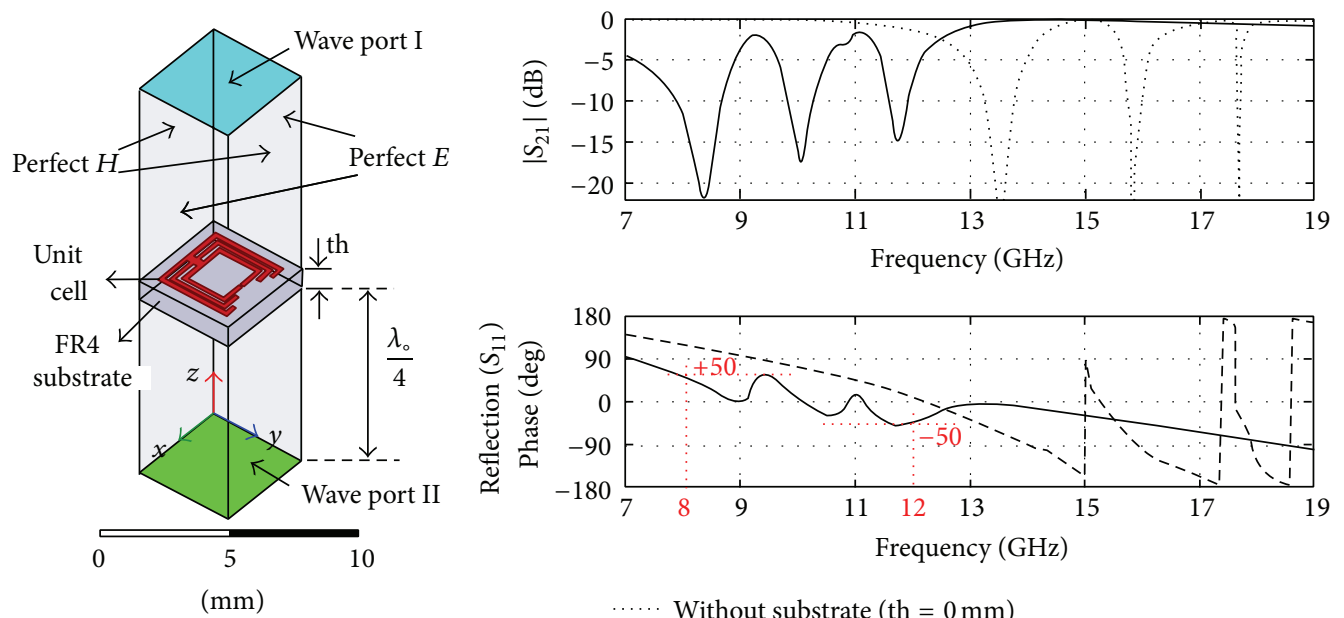

Without substrate $(\mathrm{th}=0 \mathrm{~mm})$

- th $=0.8 \mathrm{~mm}$

FIGURE 3: Reflected-wave unit-cell box study setup and the related results, $S_{21}$ and the phase $\left(S_{11}\right)$.
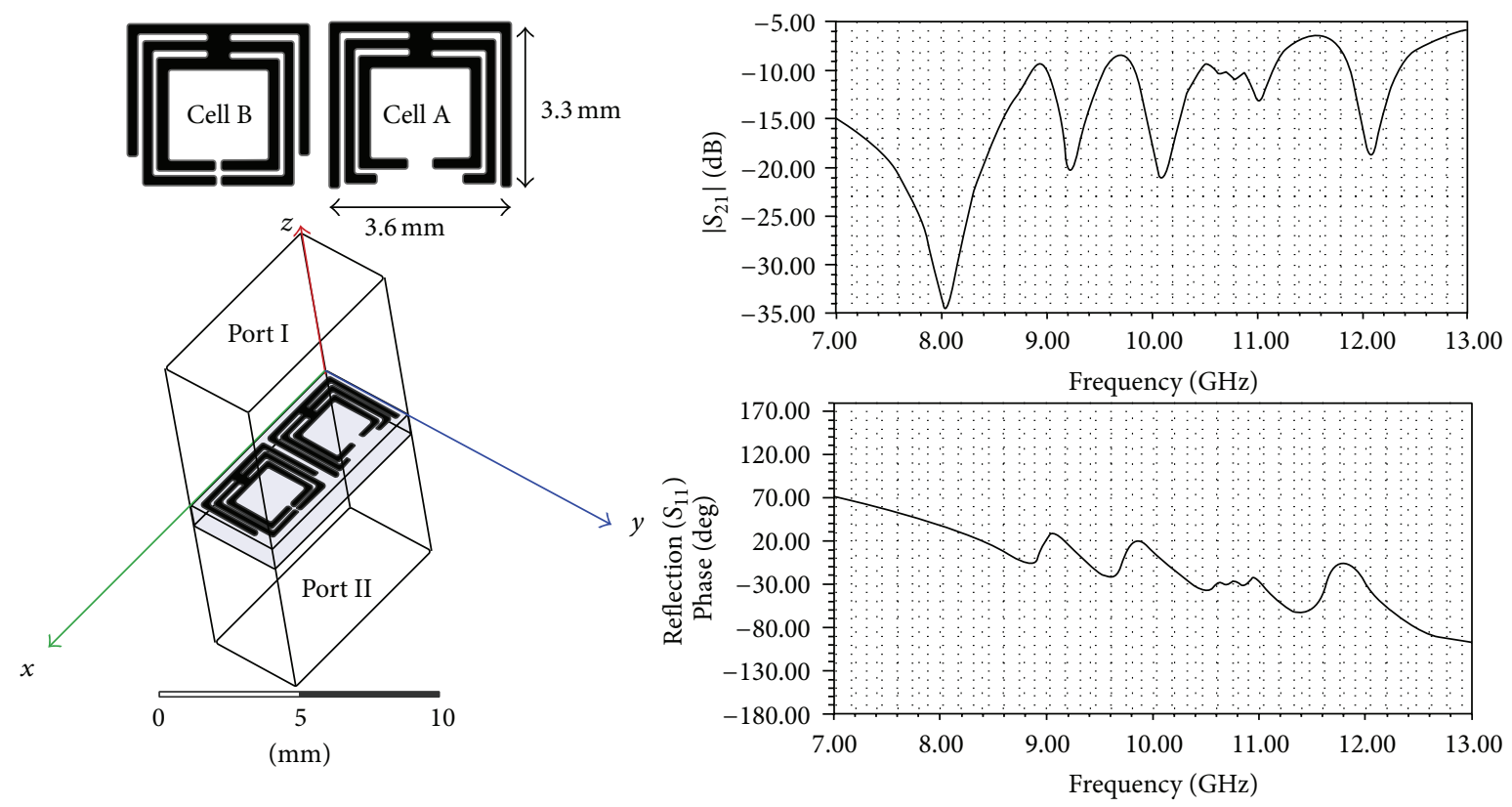

FIgURE 4: Reflected-wave unit-cell box study setup of the double cells, dimensions, and the related results, $S_{21}$ and the phase of $S_{11}$.

respectively. The other dimensions of the cell are constant, compared to the first cell. Here, the resonances at 8.8, 10.8, and $11.4 \mathrm{GHz}$ are excited. It is noted that, in this compound structure, there is electromagnetic coupling between the rings that results in a low change in the position of the resonances. In this case, two designed cells, A and B, are combined side by side to achieve a new configuration of the FSS cell and hence obtain multiresonance performance. The study setup and the results are presented in Figure 4 . It can be seen from $\mathrm{S}_{21}$ graph that six resonances are excited and the $\mathrm{X}$-band is covered with better quality. A flat phase response $\left( \pm 45^{\circ}\right)$ of the reflection coefficient $\left(S_{11}\right)$ can be seen over the whole band. Hence, the linear phase response was improved inside the band compared to the single cell result.
In the final step of the FSS study, the proposed doublecell FSS is repeated continuously and arranged in an array format to achieve the FSS screen. The final screen is shown in Figure 5. It is expected that the designed FSS can properly reflect the received fields at the mentioned resonances of the compound FSS from the front side of the slot antenna into the other side of the antenna. This results in a good accumulation for two groups of the in-phase fields, radiated from the slot antenna and reflected by FSS screen, simultaneously. Hence, the gain increment can be obtained in the mentioned direction or the other side of the slot antenna where the FSS screen is not there. The structure is analyzed by using the mentioned technique in the previous sections. The study setup and the results are presented in Figure 5. The selected periodicity is 

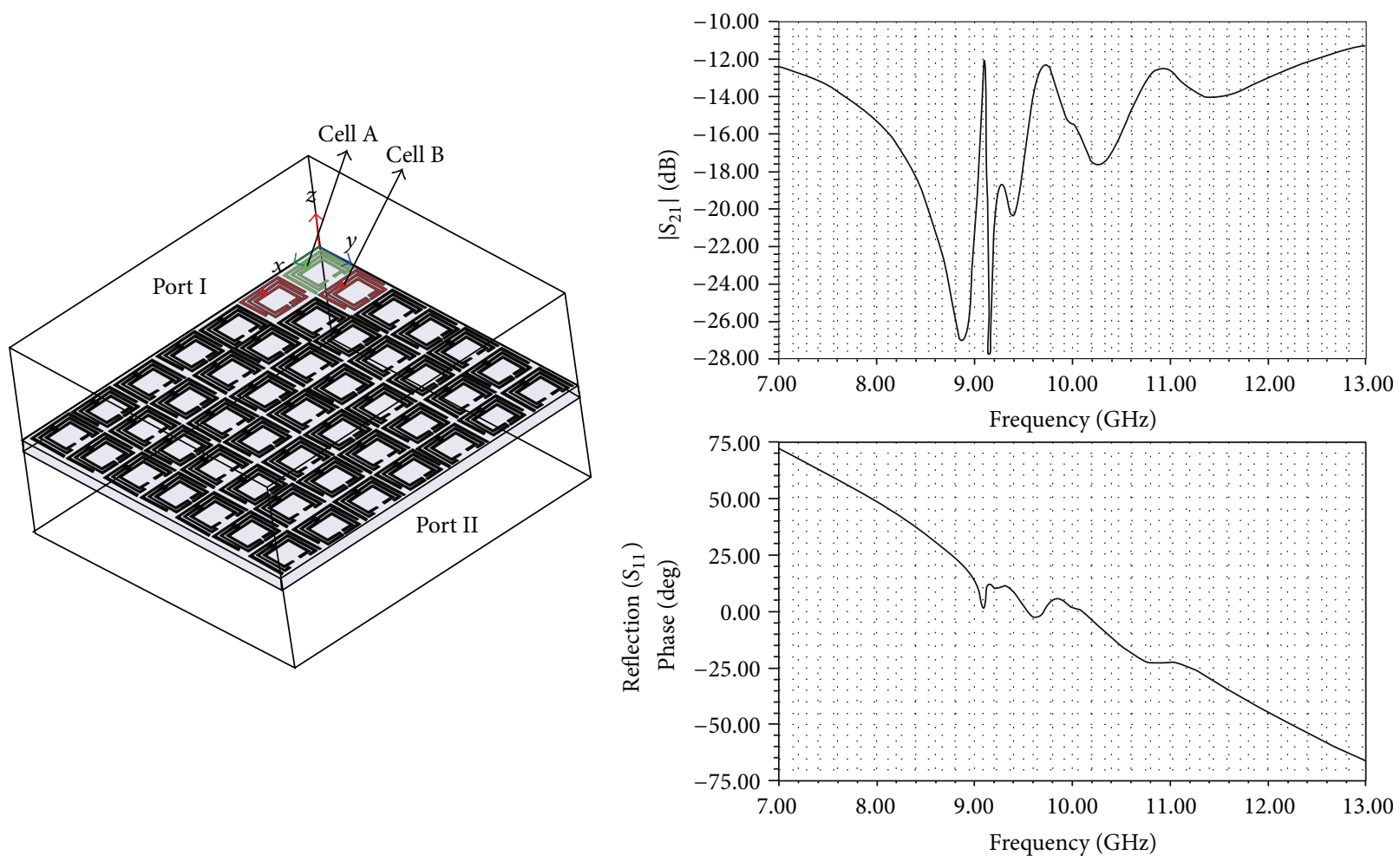

FIGURE 5: Reflected-wave unit-cell box study setup of the FSS screen and the related results, $S_{21}$ and the phase $\left(S_{11}\right)$.

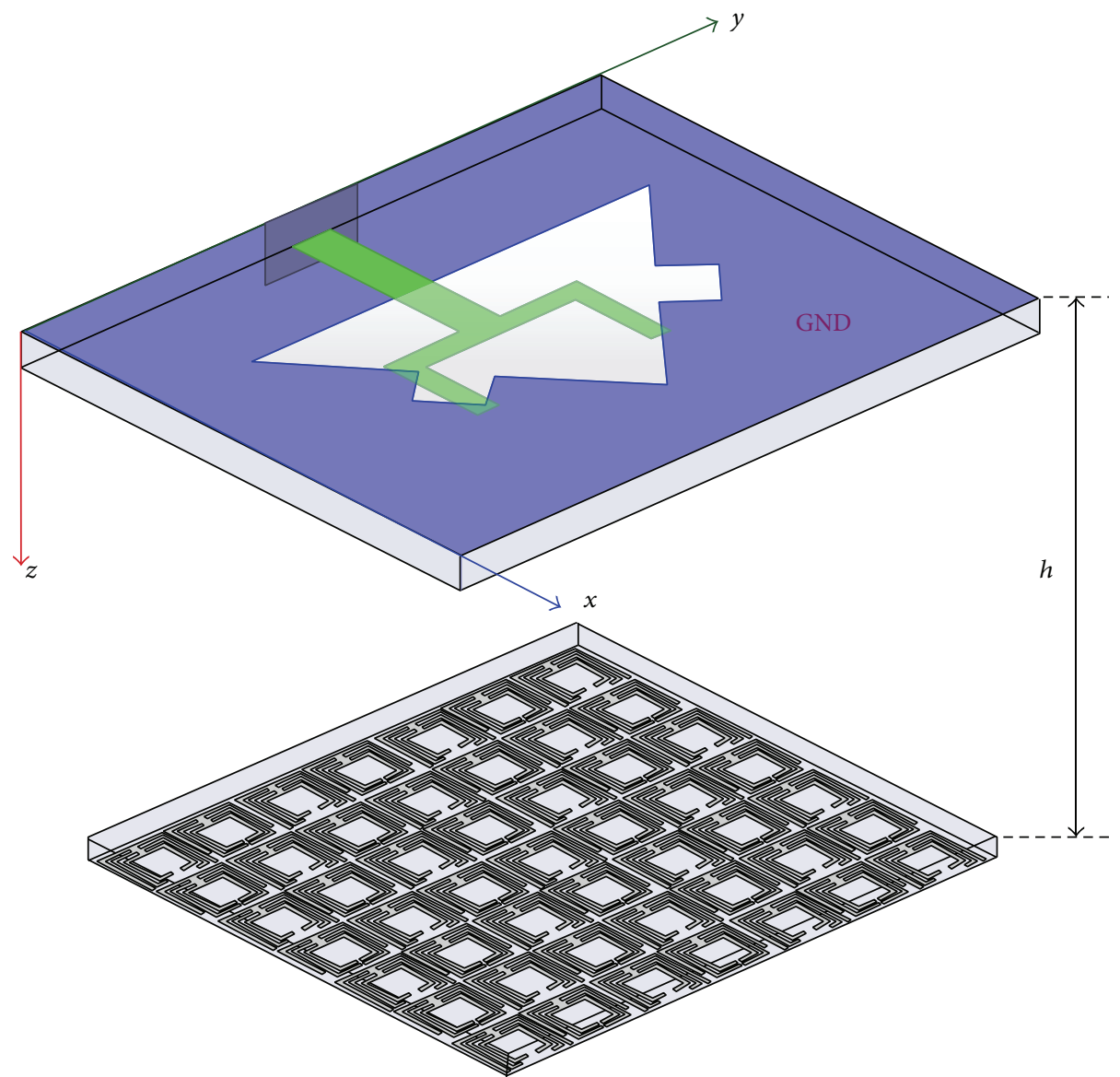

FIGURE 6: Configuration of the slot antenna with the proposed FSS screen. 

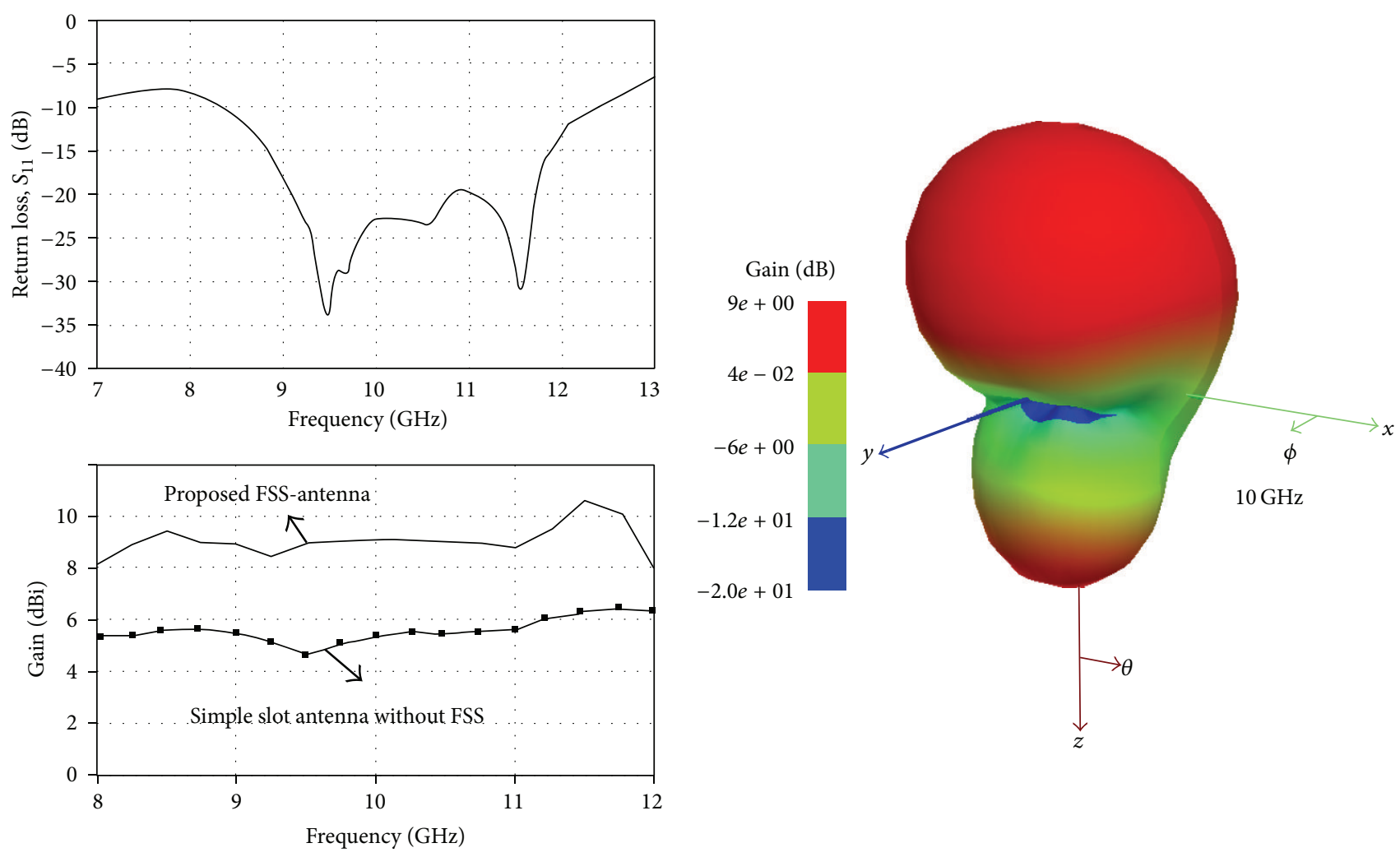

FIGURE 7: Gain, return loss, and 3D gain of the FSS-antenna, shown in Figure 6.

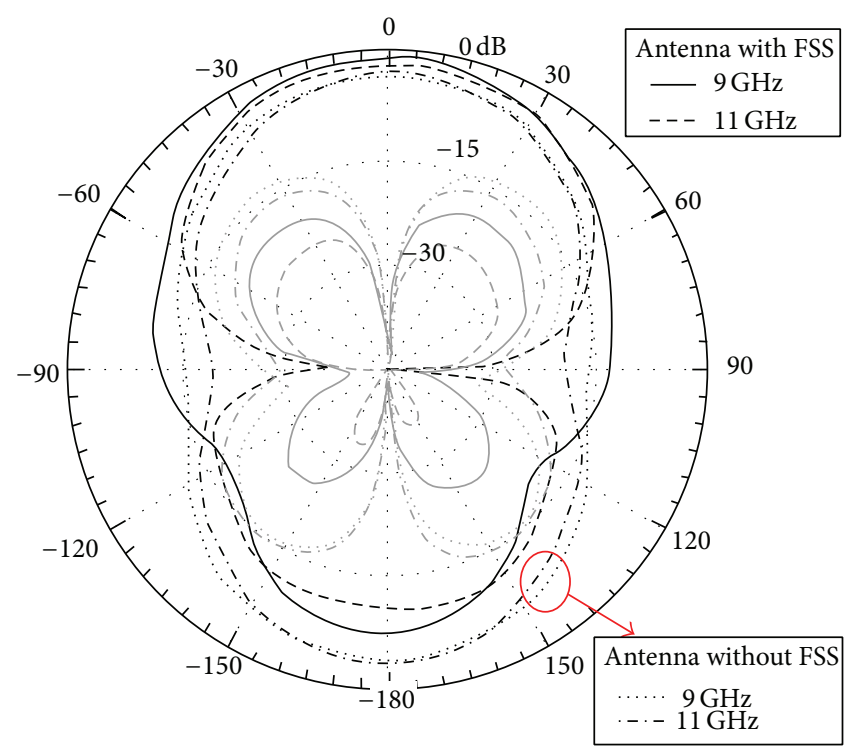

Co-pol

Cross-polar

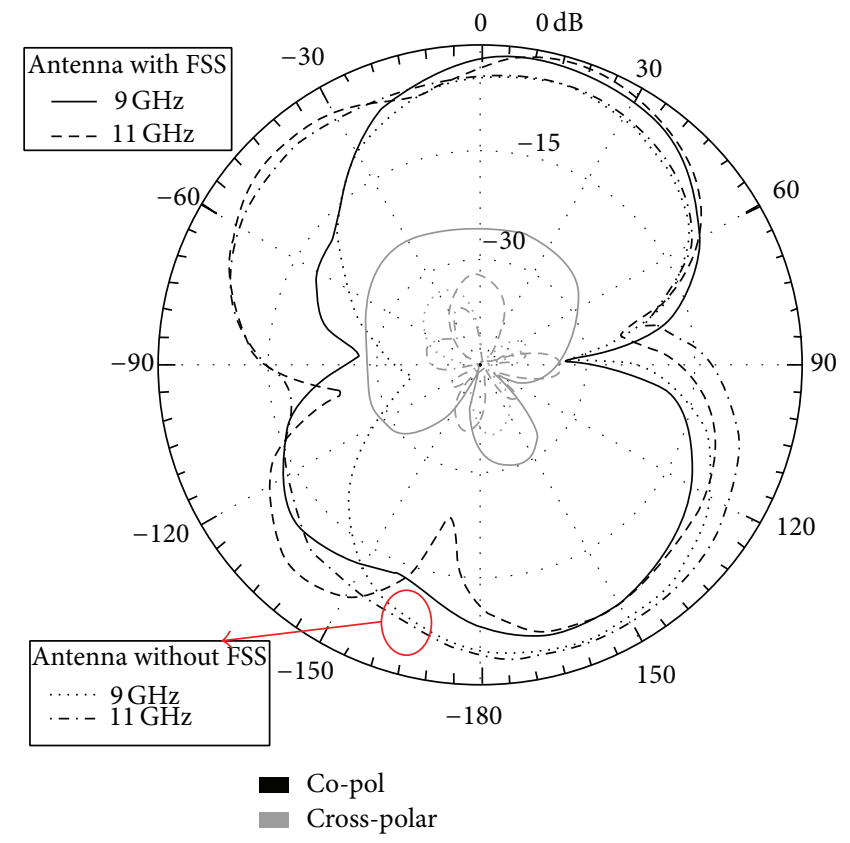

(b)

FIGURE 8: Radiation patterns of the antenna with and without FSS: (a) H-plane ( $x$ - $z$ plane) and (b) E-plane ( $y$ - $z$ plane) at 9 and 11 GHz $\left(0^{\circ} \equiv-z\right.$-axis at Figure 7$)$. 


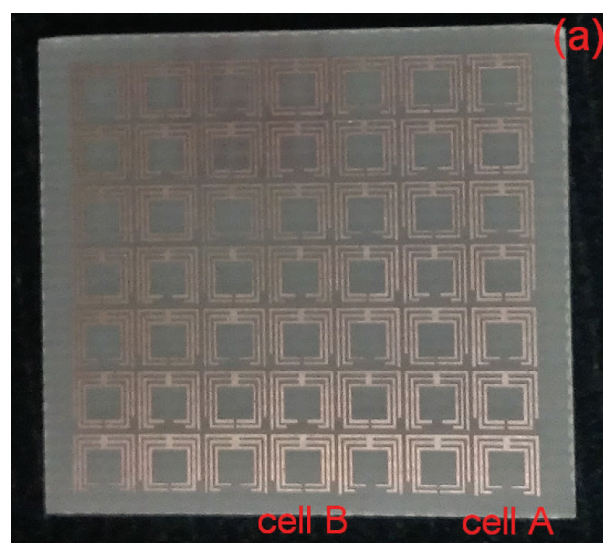

(a)
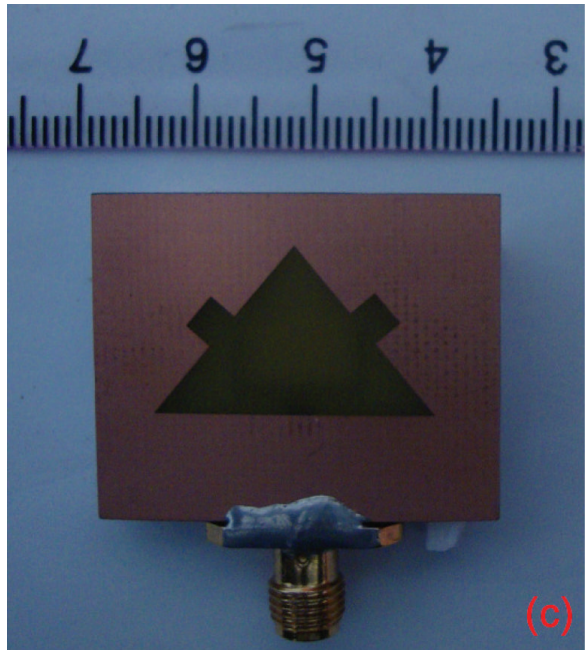

(c)

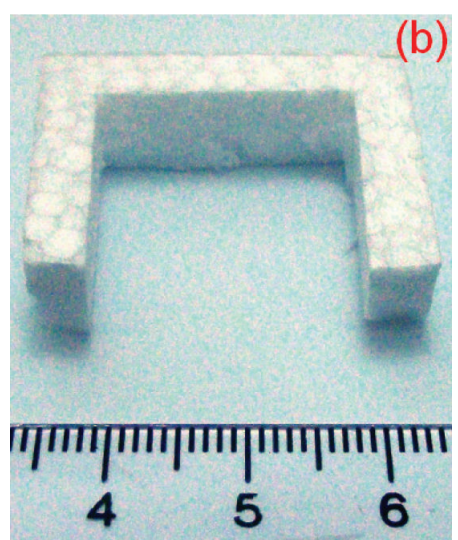

(b)

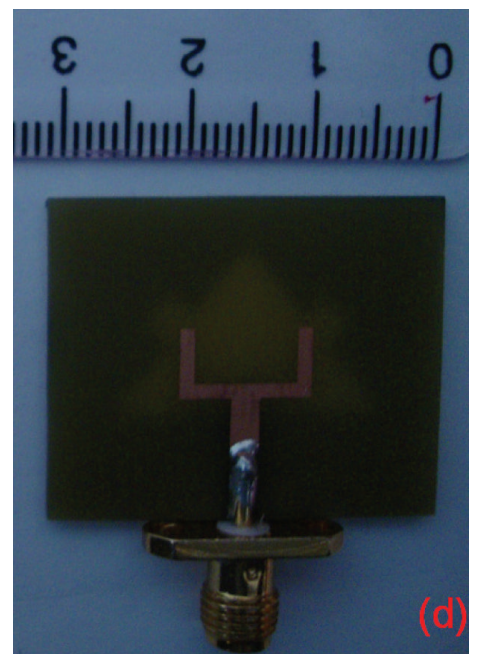

(d)

Figure 9: Photographs of the (a) FSS, (b) foam-based isolator, and (c) and (d) fabricated slot antenna.

about 3.8 and $3.5 \mathrm{~mm}$ for the $x$ and $y$ directions, respectively. By using these selected values, the better results including the linear phase of the $S_{11}$ and acceptable magnitude of the $S_{21}$ are possible. It is found out that by increasing the periodicity the lower gain enhancement is achieved. Figure 5 shows that a flat phase response $\left( \pm 47^{\circ}\right)$ of the $S_{11}$ is achieved inside the band.

3.3. Analysis of the FSS-Antenna Combination. In this step of the design, the FSS designed in the previous section is located on top of the antenna surface with a distance of $h$. It is noted that the distance is used to achieve in-phase fields in the other side of the slot antenna and accumulate the fields with possible high amplitudes. This combination is illustrated in Figure 6. The proposed FSS as a good and multiresonance reflector is located at the back of the radiating aperture, inserted in the ground plane to improve the gain inside the X-band with the maximum possible coverage. Therefore, the stable gain improvement is possible. The results of the compound structure are presented in Figure 7. The impedance bandwidth with very good matching is about $38 \%$ for $\mathrm{S}_{11}<-10 \mathrm{~dB}$ from 8.3 to $12.3 \mathrm{GHz}$. The simulated gain is between 8 and $10.5 \mathrm{dBi}$, which shows very good enhancement of the gain with minimum amplitude ripple. Here, the maximum ripple of the gain is about $2 \mathrm{~dB}$, which is very desirable. In addition, as can be seen in Figure 7, the gain enhancement of about 3.5 4 dB in comparison with the simple slot antenna without FSS is achieved. 3D-gain pattern of the antenna at $10 \mathrm{GHz}$ is also shown in the figure. This clarifies very good improvement of the gain inside the band in thet $a=180 \mathrm{deg}$ or the front direction of the FSS screen. It must be noted that the best value for the parameter $h$ is about $7.5 \mathrm{~mm}\left(0.25 \lambda_{0}\right)$ at $10 \mathrm{GHz}$. It is not shown here but by increasing $h$ from 2 to $8 \mathrm{~mm}$ the lowest edge of the bandwidth is decreased considerably and also the gain of the antenna is enhanced, while, by selecting $h$ more than $10 \mathrm{~mm}$, the gain value is decreased, sensibly. Therefore, the best selection for $h$ is about $7.5 \mathrm{~mm}$.

Figure 8 shows the radiation patterns of the antenna with and without FSS at 9 and $11 \mathrm{GHz}$. A good difference $(\approx 20 \sim$ $25 \mathrm{~dB}$ ) between co- and cross-components was obtained. In both of the $\mathrm{H}$ and $\mathrm{E}$ planes, the directive gain of the antenna with FSS has been improved about $3.5 \mathrm{~dB}$ in the broadside near thet $a=0^{\circ}$ ( $\equiv$ the opposite direction of the FSS 


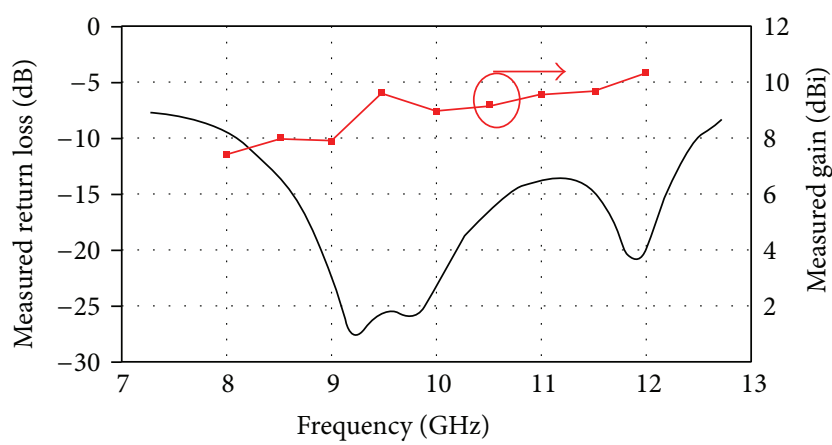

FIGURE 10: Measured return loss and directive gain of the fabricated antenna.

position ( $-z$-axis)), compared to the simple antenna with semi-monopole-like patterns. This shows that the FSS screen is like a good reflector to the slot antenna inside the Xband. Here, the simulated radiation efficiencies (as well as directivity) of the antenna with and without FSS are $88 \%$ (D: $5.22 \mathrm{~dB}$ ) and $92 \%(\mathrm{D}: 3.13 \mathrm{~dB}$ ) at $9 \mathrm{GHz}$ and $84 \%$ (D: $6.46 \mathrm{~dB})$ and $85 \%(\mathrm{D}: 3.65 \mathrm{~dB})$ at $11 \mathrm{GHz}$, respectively. These results show a negligible reduction in the efficiency and an apparent increase in the directivity.

\section{Manufacturing and Measurement}

The designed slot antenna and FSS screen were manufactured and their photographs are illustrated in Figures 9(a), 9(c), and 9(d). In order to establish the FSS screen on top of the antenna surface, a U-shaped foam-based isolator/holder with thickness of about $7.5 \mathrm{~mm}$ was fabricated, as shown in Figure 9(b). This isolator was embedded between the antenna surface and FSS. The measured return loss of the prototype was obtained using an Agilent-8722ES VNA. In the gain measurement process in the direct trajectory $[+z$-axis $]$, a standard horn antenna as a constant-power transmitter with a gain of about $15 \mathrm{~dB}$ was used exactly in front of the slot antenna in a distance of $100 \mathrm{~cm}$. A power meter in the input port of the antenna was used to detect the power, transmitted by the horn antenna in some frequencies inside the band. The obtained results are shown in Figure 10. The measured impedance bandwidth is from 8.2 to $12.4 \mathrm{GHz}$ for $\mathrm{S}_{11}<-10 \mathrm{~dB}$. A good agreement between the simulated and measured impedance results is shown. As can be seen in the figure, the measured directive gain is varied from 7.5 to $10.3 \mathrm{dBi}$. Gain enhancement of about $2.5 \sim 3 \mathrm{~dB}$ in the direct line, compared to the simulated gain of the simple slot antenna, is obtained. Moreover, the matching and bandwidth of the antenna-FSS are not very affected, compared to the single slot antenna (see Figure 2(b), the optimum case).

\section{Conclusion}

A triangle slot antenna and a new FSS screen with multiresonance characteristics have been proposed. Parametric studies were done. We showed that by designing two FSS cells with the different resonances side by side a final FSS screen with multiresonances is achieved. In this case, the X-band was properly covered. We showed that this combination of the FSS screen and the slot antenna can enhance the directive gain of the antenna about $3 \mathrm{dBi}$. It was also noted that the multiband behavior and the broadband gain enhancement were obtained when only one layer of the FSS is used. In addition, the total thickness of the proposed antenna-FSS is about $8.5 \mathrm{~mm}\left(\approx 0.28 \lambda_{0}\right)$ that is slightly thickened for $10 \mathrm{GHz}$. Finally, the proposed antenna along with the single layer multiband FSS can be a good candidate for gain-enhanced antenna applications.

\section{Conflict of Interests}

The author declares that there is no conflict of interests regarding the publication of this paper.

\section{References}

[1] B. A. Munk, Frequency Selective Surfaces: Theory and Design, Wiley, New York, NY, USA, 2000.

[2] A. K. Zadeh and A. Karlsson, "Capacitive circuit method for fast and efficient design of wideband radar absorbers," IEEE Transactions on Antennas and Propagation, vol. 57, no. 8, pp. 2307-2314, 2009.

[3] G. Virone, R. Tascone, G. Addamo, and O. A. Peverini, "A design strategy for large dielectric radome compensated joints," IEEE Antennas and Wireless Propagation Letters, vol. 8, pp. 546-549, 2009.

[4] C. Mias, C. Tsakonas, and C. Oswald, "An investigation in to the feasibility of designing frequency selective surface windows employing periodic structures," Tech. Rep. AY3922, Nottingham Trent University, Nottingham, UK, 2001.

[5] C. R. Simovski, P. de Maagt, and I. V. Melchakova, "Highimpedance surfaces having stable resonance with respect to polarization and incidence angle," IEEE Transactions on Antennas and Propagation, vol. 53, no. 3, pp. 908-914, 2005.

[6] X. L. Bao, G. Ruvio, M. J. Ammann, and M. John, "A novel GPS patch antenna on a fractal hi-impedance surface substrate," IEEE Antennas and Wireless Propagation Letters, vol. 5, no. 1, pp. 323-326, 2006.

[7] Y. Ranga, K. P. Esselle, L. Matekovits, and S. G. Hay, "Increasing the gain of a semicircular slot UWB antenna using an FSS reflector," in Proceedings of the 2nd IEEE-APS Topical Conference on Antennas and Propagation in Wireless Communications (APWC '12), pp. 478-481, Cape Town, South Africa, September 2012.

[8] Y.-J. Kim, S.-S. Nam, and H.-M. Lee, "Frequency selective surface superstrate for wideband code division multiple access system," in Proceedings of the European Wireless Technology Conference (EuWIT '09), pp. 33-36, Rome, Italy, September 2009.

[9] H. Vettikalladi, O. Lafond, and M. Himdi, "High-efficient and high-gain superstrate antenna for $60-\mathrm{GHz}$ indoor communication," IEEE Antennas and Wireless Propagation Letters, vol. 8, pp. 1422-1425, 2009.

[10] A. Foroozesh and L. Shafai, "Investigation into the effects of the patch-type FSS superstrate on the high-gain cavity resonance antenna design," IEEE Transactions on Antennas and Propagation, vol. 58, no. 2, pp. 258-270, 2010. 
[11] J. P. Gianvittorio, J. Romeu, S. Blanch, and Y. Rahmat-Samii, "Self-similar prefractal frequency selective Surfaces for multiband and dual-polarized applications," IEEE Transactions on Antennas and Propagation, vol. 51, no. 11, pp. 3088-3096, 2003.

[12] J. Yeo and R. Mittra, "Numerically efficient analysis of microstrip antennas using the characteristic basis function method (CBFM)," in Proceedings of the IEEE Antennas and Propagation Society International Symposium, vol. 4, pp. 85-88, usa, June 2003.

[13] H.-Y. Chen and Y. Tao, "Performance improvement of a U-slot patch antenna using a dual-band frequency selective surface with modified Jerusalem cross elements," IEEE Transactions on Antennas and Propagation, vol. 59, no. 9, pp. 3482-3486, 2011.

[14] D. J. Kern, D. H. Werner, A. Monorchio, L. Lanuzza, and M. J. Wilhelm, "The design synthesis of multiband artificial magnetic conductors using high impedance frequency selective surfaces," IEEE Transactions on Antennas and Propagation, vol. 53, no. 1, pp. 8-17, 2005.

[15] E. Moharamzadeh and A. M. Javan, "Triple-band frequencyselective surfaces to enhance gain of $\mathrm{x}$-band triangle slot antenna," IEEE Antennas and Wireless Propagation Letters, vol. 12, pp. 1145-1148, 2013.

[16] M. Rad, C. Ghobadi, J. Nourinia, and R. Zaker, "A small printed ultra-wideband polygon-like wide-slot antenna with a fork-like stub," Microwave Journal, vol. 53, no. 3, pp. 118-123, 2011. 

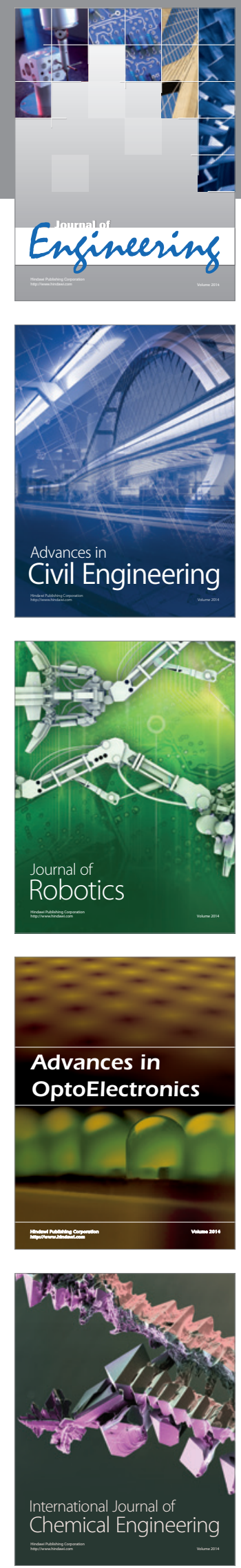

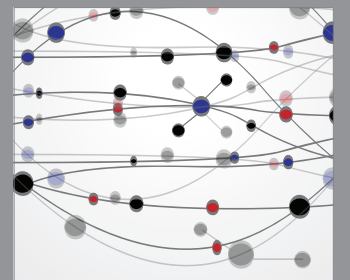

The Scientific World Journal
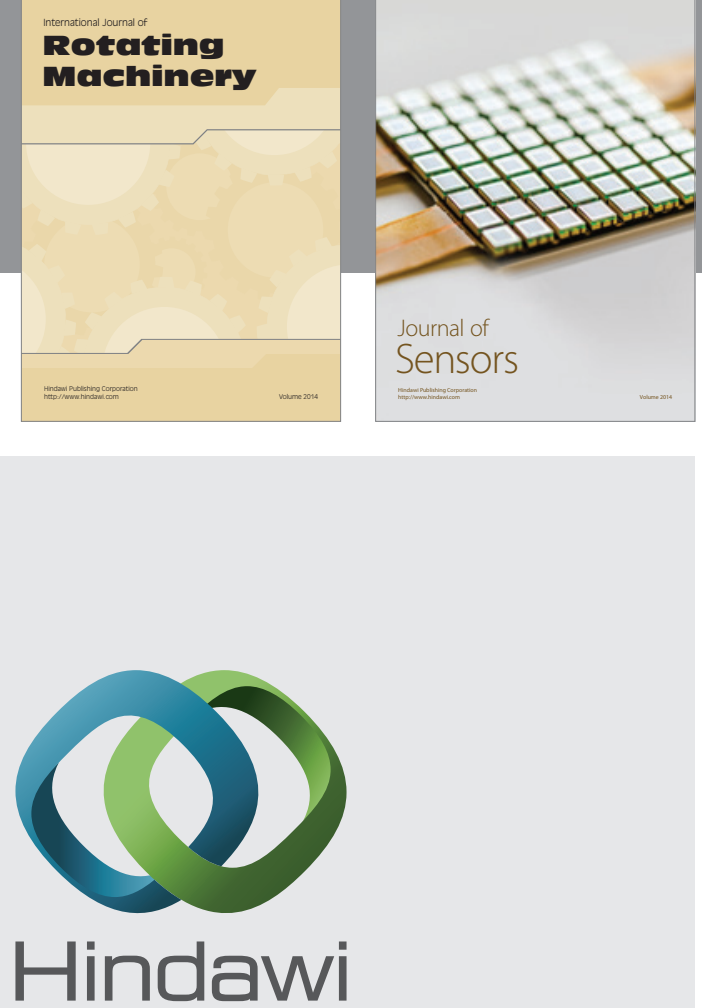

Submit your manuscripts at http://www.hindawi.com
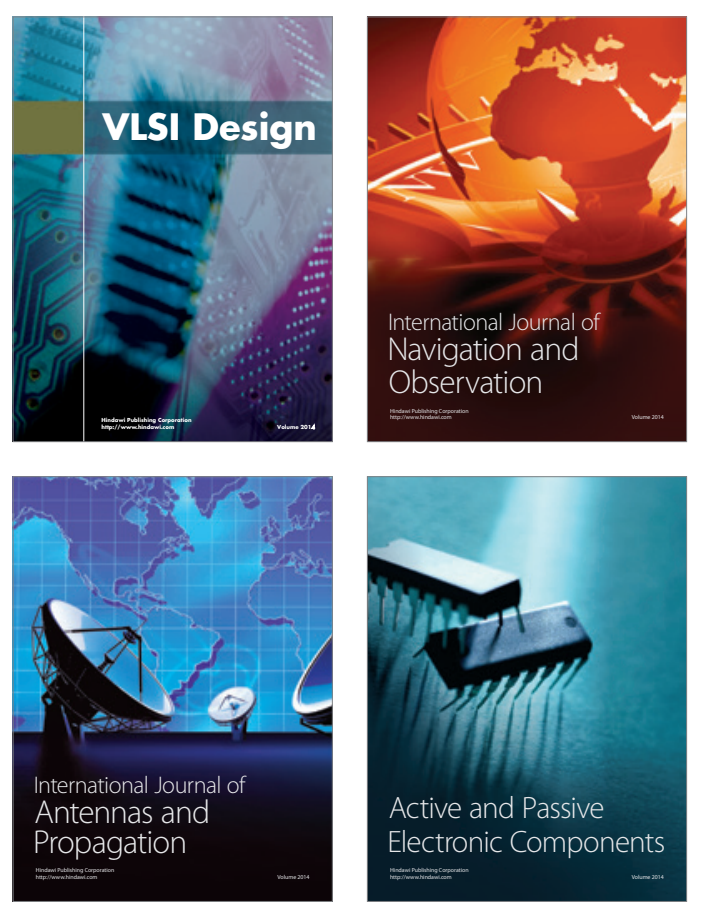
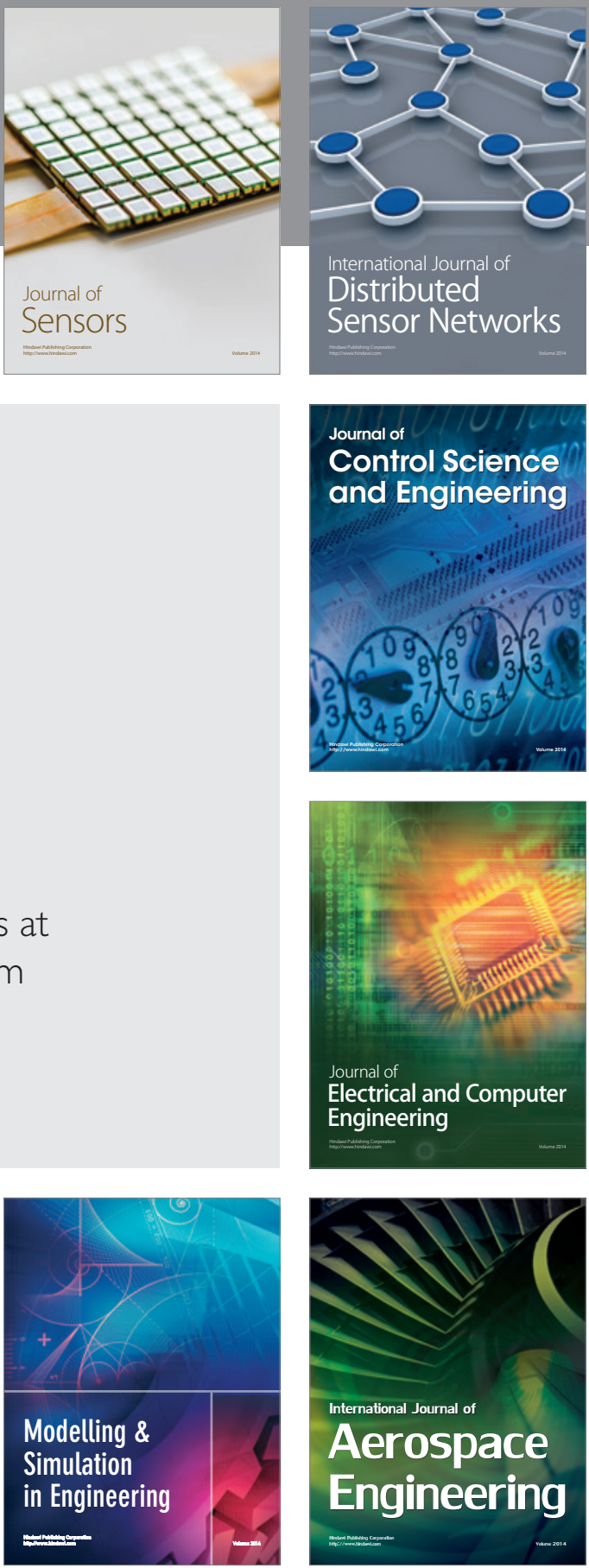

Journal of

Control Science

and Engineering
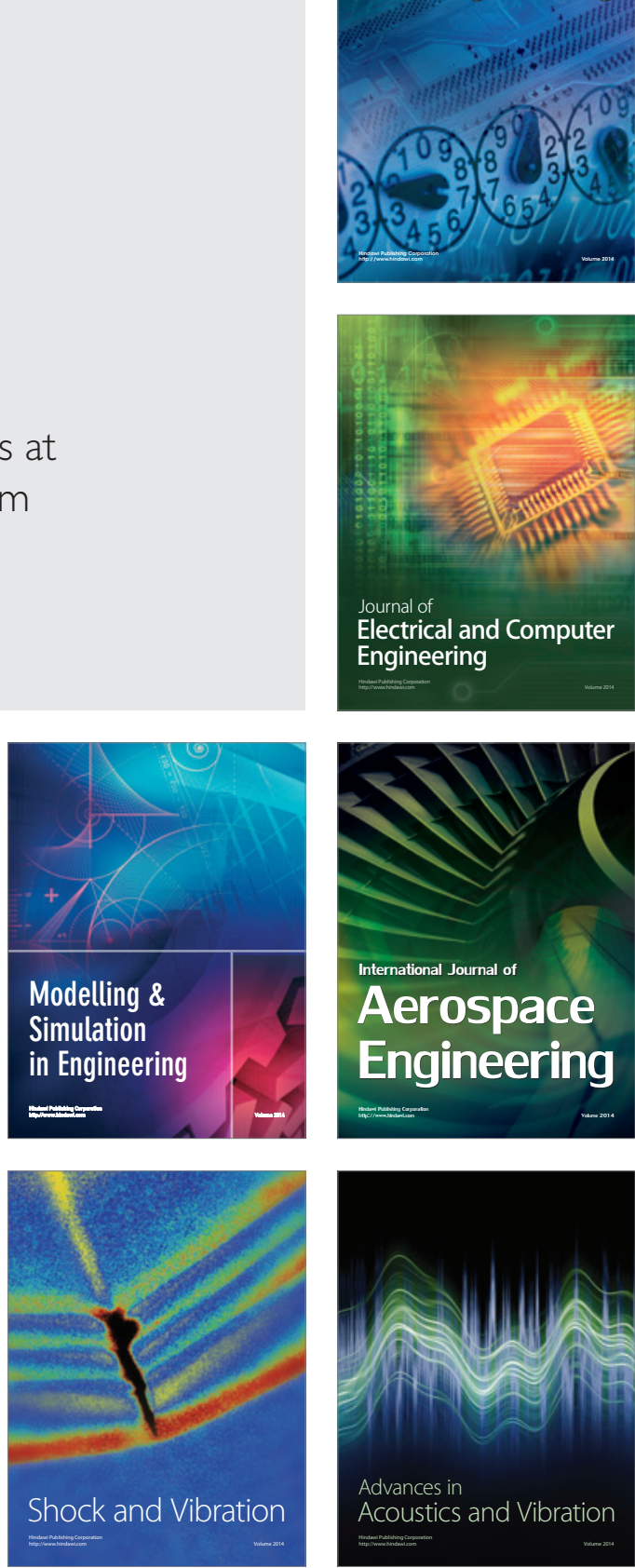